\title{
Popping characteristics of paddy using microwave energy and optimization of process parameters
}

\author{
Ajay Kumar Swarnakar ${ }^{\mathrm{a}}$, M. KAlPana Devi ${ }^{\mathrm{a}}$, AND S. K. DAS ${ }^{\mathrm{a}^{*}}$ \\ a Agricultural and Food Engineering Department, Indian Institute of Technology, Kharagpur 721302, West \\ Bengal, India \\ ${ }^{*}$ Corresponding author \\ skd@agfe.iitkgp.ernet.in \\ TEL: $+97-3222-2831125$
}

Received: 25 June 2013; Published online: 18 April 2014

\begin{abstract}
Microwave popping characteristics of a particular variety of paddy were studied using a domestic microwave oven. The experiments were carried out at 4 levels of moisture content (around 13\%, 14\%, $15 \%$ and $16 \% \mathrm{wb}), 3$ levels of power $(600 \mathrm{~W}, 850 \mathrm{~W}$ and $1000 \mathrm{~W})$ and 5 levels of heating time $(40 \mathrm{~s}$, $60 \mathrm{~s}, 80 \mathrm{~s}, 100 \mathrm{~s}$ and $120 \mathrm{~s}$ ). A general factorial experiment design was followed, and effect of different treatment combinations on popping percentage and expansion ratio of the paddy was evaluated. The maximum popping percentage of $63.47 \%$ was obtained at a moisture content of $14.15 \%$ and energy level of $80 \mathrm{~kJ}(1000 \mathrm{~W}$ and $80 \mathrm{~s})$ while the maximum expansion ratio of 4.42 was obtained at $14.94 \%$ moisture content and energy level of $68 \mathrm{~kJ}(850 \mathrm{~W}$ and $80 \mathrm{~s})$. Optimum values of microwave power, time of heating and moisture content of paddy were achieved at $1000 \mathrm{~W}, 80 \mathrm{~s}$ and $15 \%$, respectively, corresponding to popping percentage and expansion ratio of 58.73 and 3.58 .
\end{abstract}

Keywords: Popped rice; Microwave; Paddy; Optimized popping condition; Grain puffing 
46 Swarnakar et al.

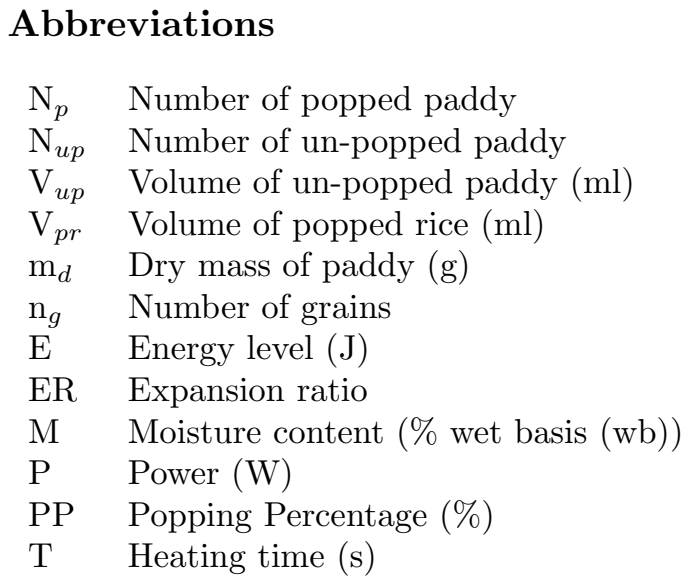

\section{Introduction}

Popped rice is one of the earliest known ricebased popular traditional ready-to-eat breakfast cereal products in South-East Asia (Bhat Upadya, Bhat, Shenoy, \& Salimath, 2008). The whole grain produce contributes numerous beneficial nutrients for human health including dietary fibre, vitamins, minerals and phytochemicals (Maisont \& Narkrugsa, 2009). Traditionally, it is prepared by intense conduction heating (roasting) of paddy at the proper moisture content on a vigorously agitated hot sand bed. This causes conversion of moisture within the pericarp into steam almost instantly and the pressure builds up to about 135 psi (at around $170^{\circ} \mathrm{C}$ ) which ultimately leads to $6-8$ times volume expansion of the kernel that pops out from the husk (Bhat Upadya et al., 2008), followed by separation of the husk and sand particles. The large bulk volume and hygroscopic character of the popped kernel involves a huge cost in transportation, storage and packaging. Further, contamination of sand particles and other extraneous matter which are very common during handling process make the produce unfit for consumption. In addition, over heating (burning/charring) (Maisont \& Narkrugsa, 2009) and improper moisture conditioning affect the quality of final product (partially expanded or unexpanded grain) as it largely depends on the skill of the operator. Popping/puffing on hot sand bed has been replaced by gun puffing technique. However, the cost involved in the construction of the pressure vessel and its opera- tions is quite large (Nath, Chattopadhyay, \& Majumdar, 2007). Microwave energy could be well applied for baking, roasting, puffing and popping (Maisont \& Narkrugsa, 2009). Development of the process of popping corn in microwave oven has been reported and commercialized (Singh \& Singh, 1999). This technique has triggered similar research on popping of rice grains in microwave oven using pre-conditioned rice. Microwave heating (popping process) has several benefits over traditional processes regarding quick start-up time, faster heating in reaching popping temperature, energy efficient, low space requirements, selective heating, and there is no need for pressure vessel and personal skill (Maisont \& Narkrugsa, 2009).

Expansion of the kernel is the most important quality parameter for popped rice and is largely affected by several factors (Murugesan \& Bhattacharya, 1991a; Srinivas \& Desikachar, 1973). These include husk interlocking, presence of white belly in the grains, grain hardness, husk content, hydration capacity of paddy, and percentage of cracked kernels. Proper moisture content in the grain facilitates the production of required pressure inside the kernels before popping. Moisture less than optimum value decreases popping performance (Song \& Eckhoff, 1994), whereas excess moisture produces low expansion (Bhat Upadya et al., 2008). Juliano (1993) reported a moisture range of 13-17\% for popping of paddy in conventional heating at $240^{\circ} \mathrm{C}$ for $35 \mathrm{~s}$. Further, in puffing of rice, Chinnaswamy and Bhattacharya (1983) reported that 
optimum puffing could be possible with narrow moisture content range of $10.5-11 \%$ for adequate expansion of the grain. Optimum moisture content for best popping expansion was reported to be $14 \%$ for unsalted paddy and $17 \%$ moisture for salted paddy (Murugesan \& Bhattacharya, 1986, 1991b).

Mohapatra and Das (2011) have reported puffing of pre-conditioned rice using different levels of microwave energy (combination of power levels and time). It was reported that the puffing quality of rice depends on input energy and salt level in the kernels. An energy level of $29.21 \mathrm{~kJ}$ (880 $\mathrm{W}$ and $33.1 \mathrm{~s}$ ) and salt concentration of $4.6 \%$ was found to be optimum for puffing percentage and expansion ratio of $98.26 \%$ and 5.826 , respectively.

Maisont and Narkrugsa (2010) studied the effect of salt solution, moisture content (10-19\%) and microwave power $(600-800 \mathrm{~W})$ on puffing quality of rice. They observed that moisture content significantly affects the puffing quality. A moisture content of $13 \%$ gave the highest percentage of puffed grain and expansion in volume with less hardness. Power levels of $800 \mathrm{~W}$ and $600 \mathrm{~W}$ produced highest and lowest expansion volume, respectively. They further observed that kernels with high amylopectin content produced a low density product with homogeneous expanded texture, but kernels with high amylose content resulted in a hard product with low expansion.

Commercial production of retail pack microwavable popcorn is a huge success in the consumer market all over the world. A similar approach for commercial production of microwavable popped rice would be possible if optimized process parameters related to maximization of popping yield and quality (expansion and sensory score) are available. It is apparent that a knowledge gap still exists for use of microwave energy in popping of paddy, vis-à-vis the correlation between microwave energy and popping performance.

The present work aimed to study the effect of microwave energy and moisture content of paddy on percentage of popping and expansion of kernel followed by optimization of independent parameters to maximize popping.

\section{Materials and Methods}

\subsection{Raw material}

Paddy variety IR-36 was produced at the agricultural farm of the Department of Agricultural and Food Engineering, Indian Institute of Technology, Kharagpur, India. It contains $26.70 \%$ amylose, $8.11 \%$ protein, $0.65 \%$ ash for kernels containing $11.24 \%$ (wb) moisture. It is a high amylose content rice variety (Panlasigui et al., 1991). This variety of paddy gives good expansion and popping percentage with traditional popping technique. The paddy was stored for about one year for ageing and moisture equilibration as reported by Chinnaswamy and Bhattacharya (1983).

\subsection{Measurement of physical characteristics}

Length, width and breadth (thickness) of both paddy and kernel were measured using a grain shape tester (Japan, MK-100). Twenty grains were selected randomly from the lot and respective parameters were measured. Average values for each along with calculated standard deviation were obtained.

Hardness of grains was measured using a Hardness Tester (Kiya, Japan; least count $0.2 \mathrm{~kg}$ ) which compresses the grains gradually while rotating a handle until the cracking of grain occurred. The reading was noted and the measurement was carried out for different moisture grains and each experiment was replicated 20 times. Mass of grains was measured using electronic balance (Sartorius, BS3235, Germany, accuracy $0.001 \mathrm{~g}$ ) by taking different numbers of grains (paddy) at each time. This procedure was followed to assess variability in mass in the bulk sample. Measurement was carried out with 10 replications.

Moisture content of paddy was determined using standard procedure (AOAC, 1990) by heating the grains in an oven at $105^{\circ} \mathrm{C}$ for $24 \mathrm{~h}$. Previously weighed sample (about $2 \mathrm{~g}$ ) was taken in a pre-weighed aluminium box with lid. Then it was kept in an oven maintained at a set temperature followed by weighing after $24 \mathrm{~h}$ or until a con- 
48 Swarnakar et al.

stant weight was achieved. A repetition of this procedure was carried out twice for each sample, and average value was estimated.

\subsection{Moisture conditioning of paddy for popping}

Four moisture levels in the range of $13-16 \%$ with interval of $1 \%$ were chosen for popping with microwave energy, taking into considering the moisture range of $13-17 \%$ for popping of rice with conventional heating. Both expansion and percentage of popping were very low at higher moisture level $(17 \%)$ at various combinations of power and time while, at lower value of moisture level (around 13\%), both these parameters showed fluctuating values. To arrive at these respective moisture contents, a bulk paddy sample of about $0.5 \mathrm{~kg}$ was moistened by sprinkling a calculated amount of water followed by tempering overnight under cover for moisture equilibration in the grains. The moistened grain was dried in a fluidized bed dryer (Lab Dryer, Basic Technology Pvt. Ltd., India) at $70^{\circ} \mathrm{C}$ at about $2.2 \mathrm{~m} / \mathrm{s}$ air velocity. Grain was taken out periodically, cooled to room temperature and its approximate moisture content was measured by a universal moisture meter (Osaw Industrial, Model 32284, India). When the desired level of moisture was attained, the sample was taken out of the dryer, tempered for about $2 \mathrm{~h}$ for moisture equilibration throughout the whole mass of the kernel followed by measurement of final moisture content by oven drying method as described above. Attaining to moisture content exactly to the values in the desired range was not possible. The average values of these moisture contents (with standard deviations) were estimated as $12.95 \pm 0.099$, $14.15 \pm 0.11,14.94 \pm 0.19$ and $15.93 \pm 0.19 \%$ (wb). A parallel and quick assessment of paddy moisture content was also carried by indirect measurement technique with hardness of grain. In this technique, hardness values of paddy at different known moisture contents were measured with the hardness tester. A plot of hardness versus moisture content of the paddy sample was taken as reference (data not shown). Moisture content of the paddy sample was evaluated rapidly from its hardness value and this reference plot. This facilitated the evaluation of the moisture content of paddy close to target value without waiting for $24 \mathrm{~h}$ in oven drying.

The prepared sample with particular moisture content was divided in parts and packed in several self-sealing high-density polythene sachets. All these sachets were packed in an airtight plastic container. The conditioned paddy samples were then used for popping in microwave oven.

\subsection{Microwave popping}

For popping of the moisture conditioned paddy in microwave oven, the procedure described below was followed.

\section{Microwave oven}

A domestic microwave oven of $28 \mathrm{~L}$ volume (Samsung, model MI97DL, India) was used for popping of paddy with different microwave oven settings $(600 \mathrm{~W}, 850 \mathrm{~W}$ and $1000 \mathrm{~W})$ at microwave frequency of $2450 \mathrm{MHz}$.

\section{Sample preparation}

Mass of $30 \mathrm{~g}$ of conditioned paddy was taken from the prepared sample and packed in a paper pouch where its mouth was sealed before heating in the microwave oven.

\section{Power level and time of heating}

One pouch at a time was put inside the microwave oven. Power input and time of heating were set. The power levels of $600 \mathrm{~W}, 850 \mathrm{~W}$ and $1000 \mathrm{~W}$ and time of heating ranging from 40 - $120 \mathrm{~s}$ (5 levels at $20 \mathrm{~s}$ increments) were used in different combinations. After the heating period was over, the whole sample was taken out from the pouch and popping characteristics were evaluated. Each experiment with specific energy level and moisture content was repeated three times.

\subsection{Optimization of the process parameters}

For popping of the moisture conditioned paddy in microwave oven, the procedure described 
below was followed. For optimization of process parameters, experiments were conducted using three levels of power, five levels of time and four levels of moisture contents. The general factorial option for experiment design was applied for optimizing the process in Design Expert 7 software (Design expert version 7.0.0, Stat Ease INC., 2009, USA). The number of distinct combinations of the experiments was worked out to be 60 . Twelve time-power combinations (at high power level and long heating period) yielded undesirable charring of the samples. These were eliminated from the total number of experiments and thus the number of experiments was reduced.

To find out the effect of independent variable (effects, X) on dependent variable (response, $\mathrm{Y})$, the following quadratic regression equation (model) was fitted.

$$
\begin{aligned}
& Y=b_{0}+b_{1} X_{1}+b_{2} X_{2}+b_{3} X_{3}+\ldots \\
& \ldots b_{12} X_{1} X_{2}+b_{13} X_{1} X_{3}+\ldots \\
& \ldots b_{23} X_{2} X_{3}+b_{11} X_{1}^{2}+b_{22} X_{2}^{2}+b_{33} X_{3}^{2}
\end{aligned}
$$

Optimization of independent parameters, moisture level $(\mathrm{M})$, power level $(\mathrm{P})$ and heating time (T) was carried out for maximization of dependent variables, popping percentage and expansion ratio. Optimum conditions were finally selected considering the feasibility of microwave oven power and heating time combination, and maximization of multiple responses following the desirability function approach which is one of the most widely used industry methods for the optimization of multiple response processes (NIST, 2012). The method finds operating conditions $\boldsymbol{x}$ that provide the "most desirable" response values. For each response $\mathrm{Y}_{i}(\mathrm{x})$ a desirability function $\mathrm{d}_{i}\left(\mathrm{Y}_{i}\right)$ assigns numbers between 0 (completely undesirable) and 1 (completely desirable or ideal response value). Based on desirability function of each of the parameters involved $\left[\mathrm{d}_{i}\left(\mathrm{Y}_{i}\right)\right]$, the overall desirability (D) was obtained from geometric mean of the individual desirability (NIST, 2012) as:

$$
D=\left[d_{1}\left(Y_{1}\right) \times d_{2}\left(Y_{2}\right) \ldots d_{k}\left(Y_{k}\right)\right]^{1 / K}
$$

Where $\mathrm{k}$ denotes the number of responses. The designated software (Design Expert 7) was employed for optimization of parameters.

\subsection{Popping characteristics}

The popped paddy after specified energy input (power level multiplied by time) was taken out from the oven. Percentages of popping and expansion ratio were measured by following the procedures described below.

\section{Percentage of popping (PP)}

Percentage of popping was estimated as the ratio of number of popped rice to the number of actual paddy grains taken for popping multiplied by 100 . Thus,

$$
P P=\left\lfloor\left(N_{p}-N_{u p}\right) / N_{p}\right\rfloor \times 100
$$

Where $N_{p}=$ number of initial paddy grains, $\mathrm{N}_{u p}=$ number of un-popped paddy grains. Number of un-popped grains and total number of grains were estimated using correlation between weight of dry mass in grain and number of grains (Fig. 1, Eq. 4). This correlation was obtained using experimental measurement of dry mass $\left(\mathrm{m}_{d}\right)$ for known number of grains $\left(\mathrm{n}_{g}\right)$. Moisture content of initial grain (before puffing) and that for un-puffed grains (for each puffing experiment) was recorded for calculation of number of grains in the respective grain mass.

$$
m_{d}=0.0215 n_{g}+0.0181 ; R^{2}=0.99
$$

Popped grains obtained in this process were categorized into four fractions (Fig. 2). These were fully popped with open structure (Fig. 2a), popped without rupture in shape (Fig. 2b), popped with improper expansion (Fig. 2c) and un-popped (Fig. 2d). The last two categories of grains were considered un-popped, and their numbers were estimated.

\section{Expansion ratio (ER)}

Expansion ratio of popped grains is the ratio of true volume of popped rice $\left(\mathrm{V}_{p r}\right)$ to the volume of the same number of paddy grain before popping $\left(\mathrm{V}_{u p}\right)$ :

$$
E R=V_{p r} / V_{u p}
$$


$50 \mid$ Swarnakar et al.

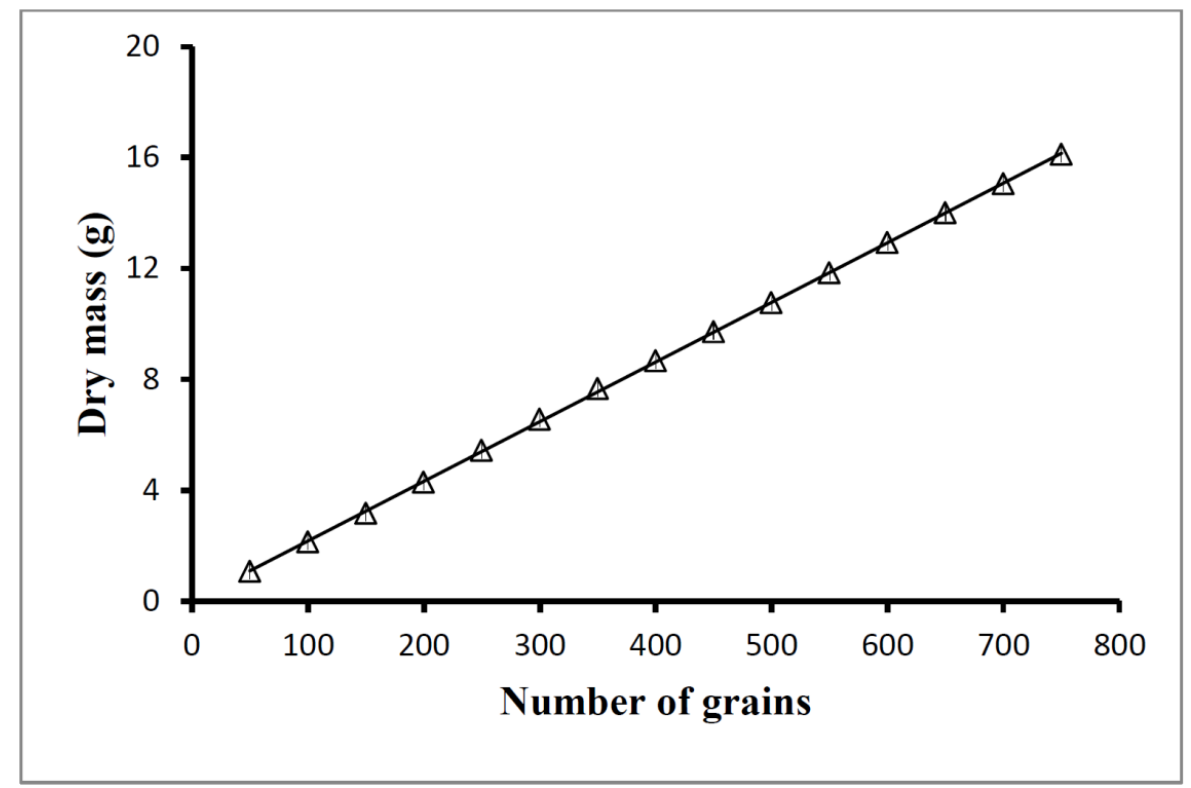

Figure 1: Correlation between dry mass in paddy and number of grains
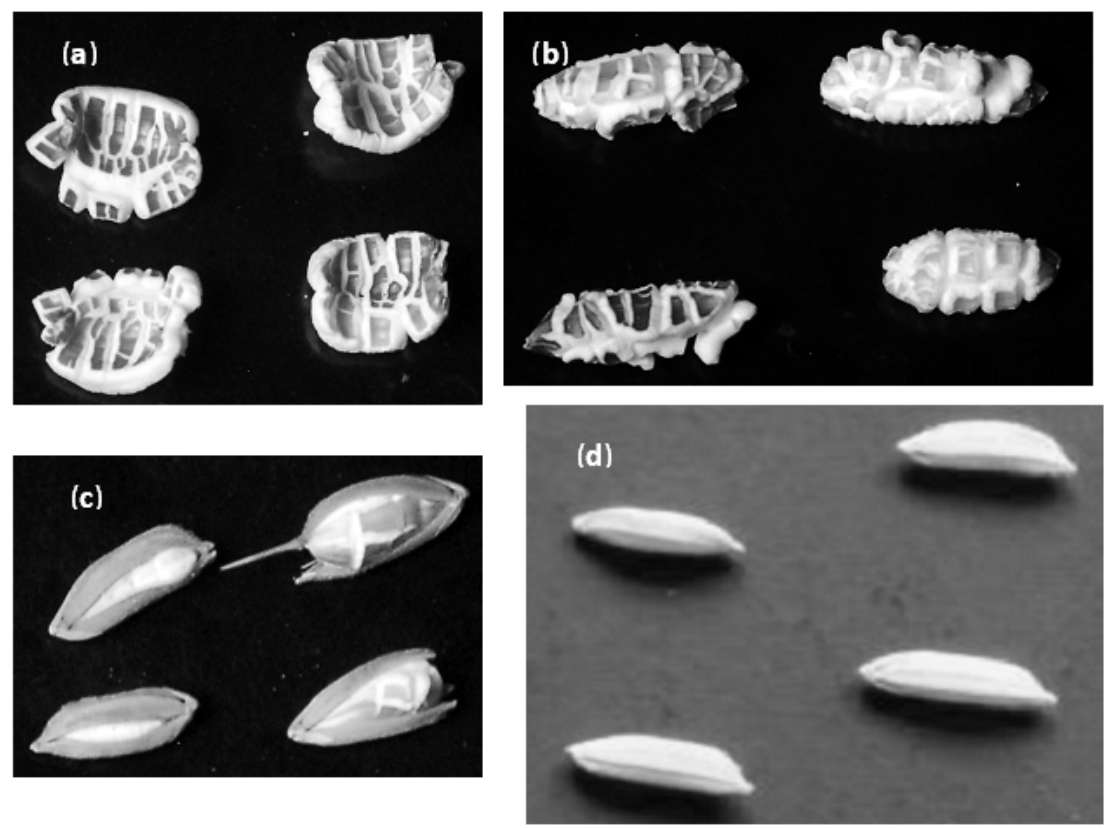

Figure 2: Different states of popping of paddy using microwave energy. (a) Fully popped with open structure, (b) Popped without rupture in shape, (c) Popped without proper expansion and (d) Unpopped paddy 
Instead of taking a single grain (popped and unpopped) for measurement of its true volume, an indirect technique was adopted for determining the volume of several popped grains together and that of same number of initial paddy. The ratio of these volumes was taken as the average expansion ratio. The procedure was as follows:

All the popped grains were taken into a measuring glass cylinder. Fine sand (passed through 100 micron screen) was taken, and it was repeatedly washed with hot chromic acid (sulphuric acid + potassium dichromate mixture) solution to remove all organic matters. It was then thoroughly washed using cleaned water and dried in an oven at $130-150^{\circ} \mathrm{C}$ for $2-3 \mathrm{~h}$. The sand was poured into the measuring cylinder with gentle tapping so as to complete fill up the void inside the mass of grains. Pouring of sand was continued until the top part of grains was covered with sand. The final volume was noted. The mass was then poured on a screen to separate sand, and the volume of sand was measured. The difference between these two volumes gives the volume of the popped grains. For estimation of volume of unpopped paddy, a similar approach was used. Average expansion ratio was calculated thereafter.

\section{Results and discussion}

Table 1 shows the physical characteristics of paddy and corresponding kernels. According to length to breadth ratio, it was categorised as long variety paddy (Chakravorty \& Ghosh, 2012). Table 2 shows quality of microwave popping of paddy at different initial moisture contents, using different combinations of power level and heating period (energy levels). The percentage of popping varied from 0.0 to $63.47 \%$, and expansion ratio varied from 0.0 to 4.42 . A combination of $600 \mathrm{~W}$ and $40 \mathrm{~s}$ of heating showed no popping at all levels of moisture content. The minimum popping $(2.12 \%)$ was observed at an energy level of $34 \mathrm{~kJ}$ and moisture content of $14.94 \%$ (wb). This corresponds to power level of $850 \mathrm{~W}$ and heating period of $40 \mathrm{~s}$. The highest popping percentage was found to be 63.47 at $14.15 \%$ moisture content (wb) with input energy level of $80 \mathrm{~kJ}(1000$ $\mathrm{W} \times 80 \mathrm{~s}$ ). Expansion ratio, as low as 1.28 was observed at moisture content of $14.94 \%$ and in- put energy of $36 \mathrm{~kJ}(600 \mathrm{~W} \times 60 \mathrm{~s})$. On the other hand, the highest expansion ratio of 4.42 was obtained at the same moisture content by applying a power level of $850 \mathrm{~W}$ and heating time of $80 \mathrm{~s}$ (68 kJ of energy).

Expansion ratio was found to be higher at initial moisture content between $14.15 \%$ and $14.94 \%$ $(\mathrm{wb})$ than that for other moisture contents except for energy levels of 36 and $48 \mathrm{~kJ}$. At both these energy levels, the popping percentage was higher with paddy moisture content of $15.93 \%$. The power level in both these energy levels was $600 \mathrm{~W}$ but with different heating time. The exact reason for this behaviour is not well understood. Further, at lower power level $(600 \mathrm{~W})$, expansion ratio was higher at $14.15 \%(\mathrm{wb})$ than that at $14.94 \%$ (wb) up to a heating time of $80 \mathrm{~s}(48$ $\mathrm{kJ})$, followed by a reversed trend as power level increased beyond $600 \mathrm{~W}$ irrespective of all the heating time used. It may be attributed to rapid vaporization of water inside the kernel at faster heating rate which builds up pressure instantly and explodes with expansion of grains (Song \& Eckhoff, 1994; Bhat Upadya et al., 2008).

Figures 3 and 4 show the effect of energy level on popping percentage and expansion ratio, respectively. Popping percentage followed a linear trend, increasing with increased microwave energy. Paddy at an average moisture content of $14.15 \%$ gave the highest percentage of popping as compared to the other three moisture contents (Fig. 3). On the other hand, the lowest popping percentage was obtained with moisture content of $12.95 \%$ (wb). Paddy with moisture contents of $14.94 \%$ and $15.93 \%$ (wb) yielded a similar magnitude of percentage popping up to an energy level around $52 \mathrm{~kJ}$ followed by a diverging trend with slightly higher value for $14.94 \%$ moisture paddy than that of $15.93 \%$. The expansion ratio increased sharply up to a certain level of input energy (around $45 \mathrm{~kJ}$ ), attaining a peak at around $65-75 \mathrm{~kJ}$, followed by a dropping trend (Fig. 4). Unlike popping percentage, maximum expansion occurred with paddy containing $14.94 \%$ moisture. 
$52 \mid$ Swarnakar et al.

Table 1: Physical characteristic of IR-36 paddy and kernel

\begin{tabular}{lcc}
\hline Characteristic parameters & Paddy & Kernel \\
\hline Length, mm & $9.841 \pm 0.44$ & $6.652 \pm 0.36$ \\
Width, mm & $3.244 \pm 0.32$ & $2.304 \pm 0.28$ \\
Breadth, mm & $2.853 \pm 0.24$ & $1.794 \pm 0.33$ \\
Length/breadth ratio & $3.487 \pm 0.479$ & $3.804 \pm 0.56$ \\
\hline
\end{tabular}

$\mathrm{M}(\%, \mathrm{wb})$ of paddy $=12.52 \pm 0.065$, kernel $=13.6 \pm 0.008$

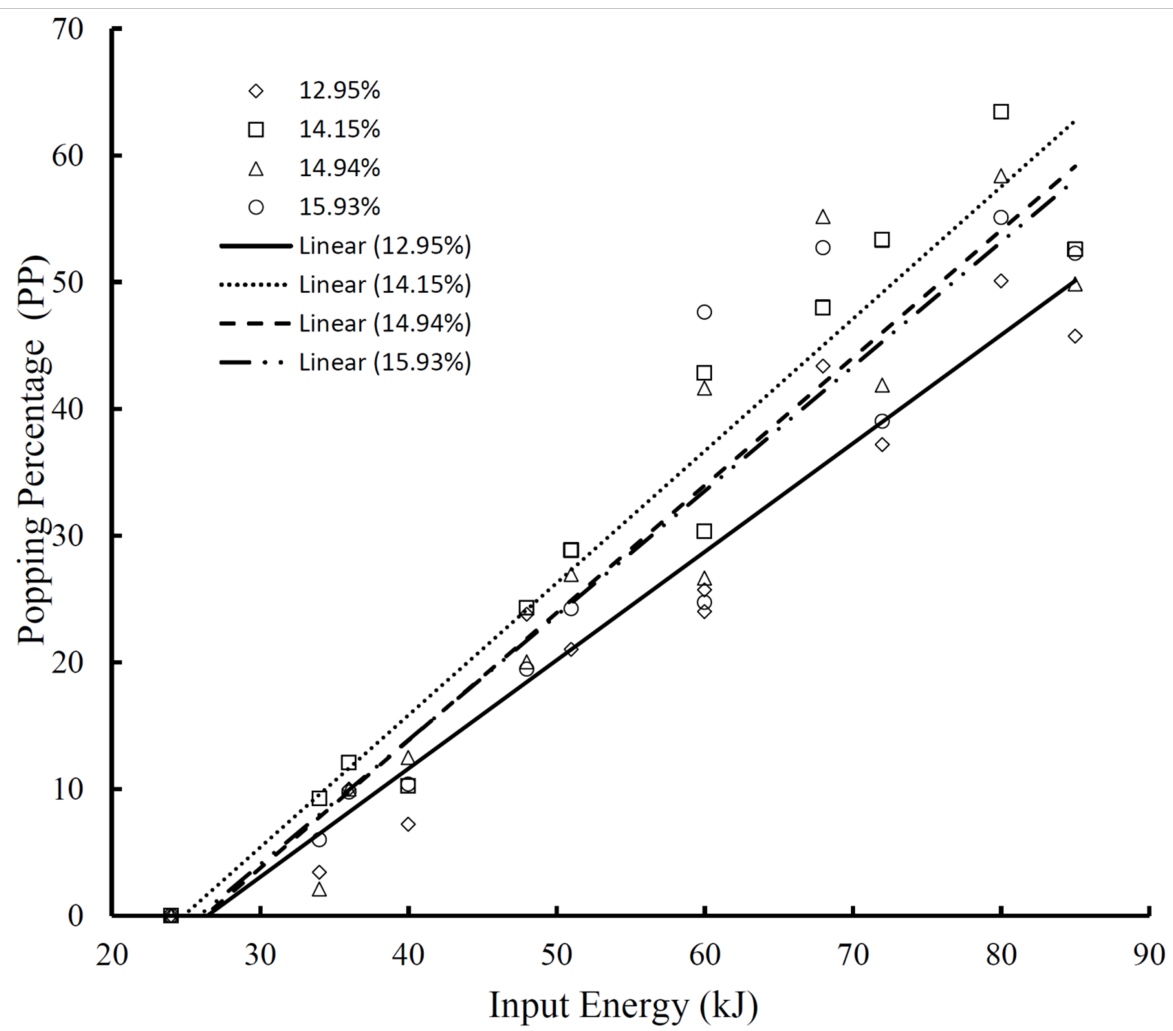

Figure 3: Effect of input energy on popping percentage 
Microwave popping characteristics of paddy $\mid 53$

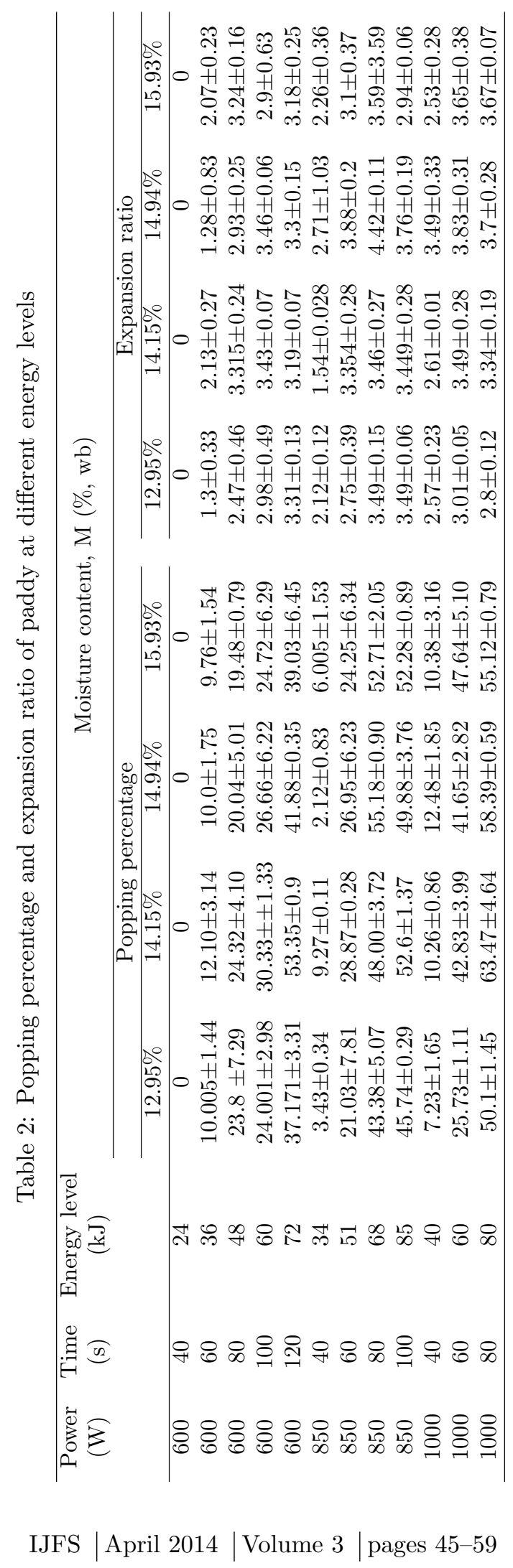


54 | Swarnakar et al.

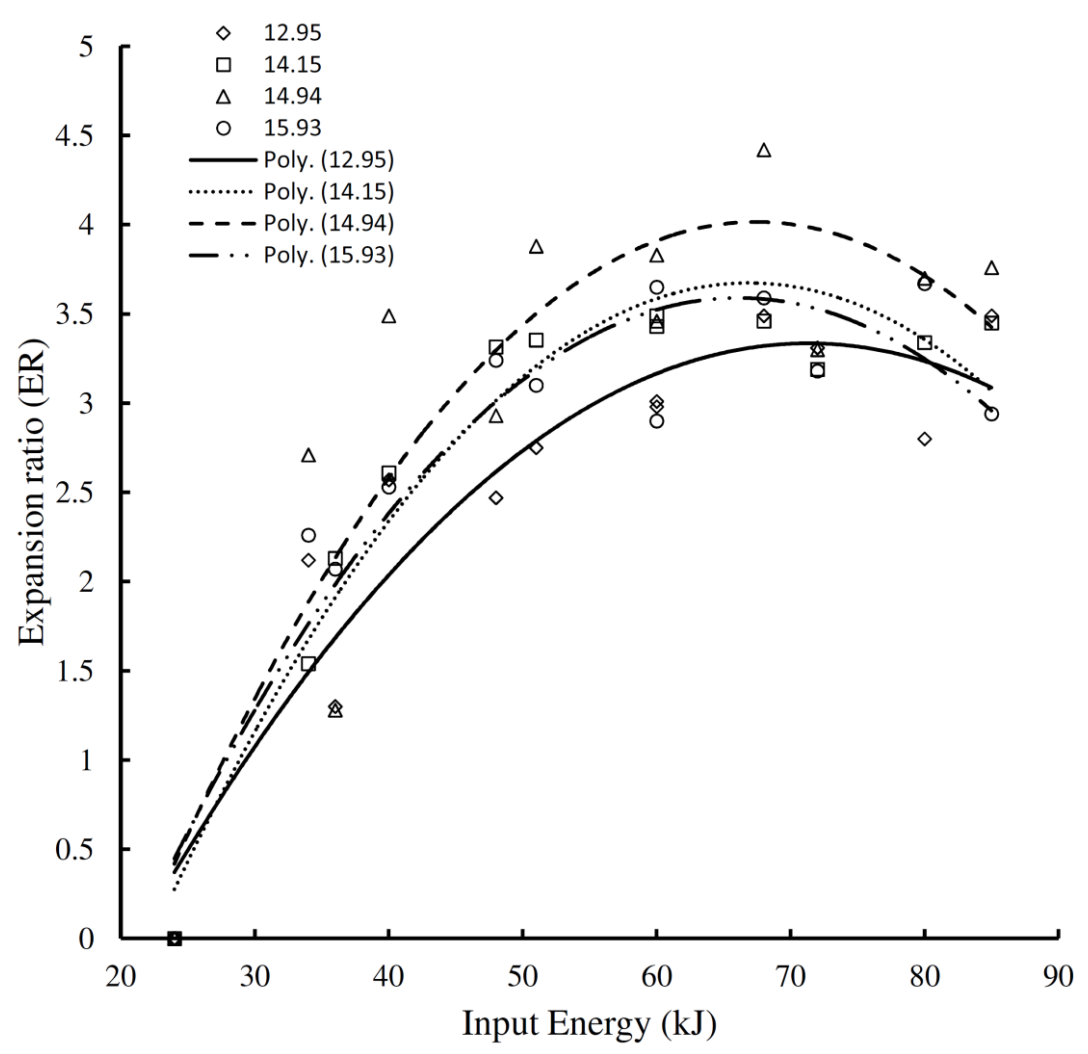

Figure 4: Effect of input energy on expansion ratio

Table 3: Relationship between input energy (E, kJ) and popping characteristics of paddy

\begin{tabular}{cll}
\hline Moisture Content, M (\%, wb) & Popping percentage $(\mathrm{PP})$ & Expansion ratio (ER) \\
\hline \multirow{2}{*}{12.95} & $\mathrm{PP}=0.8558 \mathrm{E}-22.625$ & $\mathrm{ER}=-0.0013 \mathrm{E}^{2}+0.1889 \mathrm{E}-3.4002$ \\
& $\mathrm{R}^{2}=0.933$ & $\mathrm{R}^{2}=0.913$ \\
\multirow{2}{*}{14.15} & $\mathrm{PP}=1.0426 \mathrm{E}-25.888$ & $\mathrm{ER}=-0.0018 \mathrm{E}^{2}+0.2449 \mathrm{E}-4.5928$ \\
& $\mathrm{R}^{2}=0.956$ & $\mathrm{R}^{2}=0.940$ \\
& $\mathrm{PP}=1.0071 \mathrm{E}-26.454$ & $\mathrm{ER}=-0.0019 \mathrm{E}^{2}+0.2572 \mathrm{E}-4.6569$ \\
\multirow{2}{*}{14.94} & $\mathrm{R}^{2}=0.923$ & $\mathrm{R}^{2}=0.794$ \\
& $\mathrm{PP}=0.9823 \mathrm{E}-25.413$ & $\mathrm{ER}=-0.0018 \mathrm{E}^{2}+0.2342 \mathrm{E}-4.1525$ \\
& $\mathrm{R}^{2}=0.936$ & $\mathrm{R}^{2}=0.917$ \\
\hline
\end{tabular}

$\mathrm{R}^{2}=$ Coefficient of determination

IJFS | April 2014 | Volume 3 | pages 45-59 


\subsection{Analysis of quality parameters of popped paddy}

From the foregoing discussion it is apparent that both popping percentage and expansion ratio are affected by the combined effects of time, power level of heating and moisture content of paddy. This will lead to obtaining an optimum condition for maximizing the effects. The correlations between input energy, popping percentage and expansion ratio are shown in Table 3.

\section{Popping percentage}

The regression equation, Eq. (6), in coded form for all the parameters (moisture content, power and time) is obtained after eliminating the nonsignificant terms. The estimated values of coefficient of determination $\left(\mathrm{R}^{2}\right)$, adjusted $\mathrm{R}^{2}$ and predicted $\mathrm{R}^{2}(0.933,0.9219$ and 0.9039 , respectively) are in reasonable agreement. The positive coefficients of the first order terms indicate that increase of these variables ( $\mathrm{M}, \mathrm{P}$ and $\mathrm{T})$ increased the popping percentage while the negative coefficients for quadratic terms indicate that excessive increase in these variables decreased the popping percentage. Interaction terms indicate that popping percentage increased with increase in these variables with respect to each other. The significance levels of all these linear, interaction and square terms are presented in Table 4 . The coefficient of variance (C.V.) is estimated as $18.99 \%$.

$$
\begin{aligned}
& P P=41.01+1.88 M+16.54 P+2914 T+\ldots \\
& \ldots 2.62 M P+9.0 P T-3.69 M^{2}-4.54 T^{2}
\end{aligned}
$$

Figure $5(5 \mathrm{a}, 5 \mathrm{~b})$ shows the response surface for popping percentage, keeping the third factor $\mathrm{M}$ and $\mathrm{T}$ at the central points, as $14.43 \%$ and $80 \mathrm{~s}$, respectively. These values were taken automatically by the software program (Design Expert, version 7). Popping percentage increased with both time of heating and power input. The increase was more pronounced with time of heating than with power (Fig. 5a). On the other hand, popping percentage continued to increase up to a certain range of moisture content $(14.0-14.5 \%)$ followed by a decreasing trend (Fig. 5b).

\section{Expansion ratio}

In a similar manner as that of Eq. (6), a second order polynomial relationship, Eq. (7) was obtained for expansion ratio. Table 5 shows details of analysis of variance and significance of linear, interaction and square terms. Coefficient of determination $\left(\mathrm{R}^{2}\right)$, adjusted $\mathrm{R}^{2}$ and predicted $\mathrm{R}^{2}$ (0.924, 0.910 and 0.892 , respectively) show reasonable agreement to each other. The coefficient of variance (C.V.) is $11.49 \%$. The positive coefficients of linear terms indicate that increase in these variables increased the expansion ratio. Negative coefficient of quadratic term indicates that excessive increase in power, moisture and time of heating decreased expansion ratio. Among three interaction terms, only the interaction term between power and heating time was found to be significant $(\mathrm{p}<0.01)$ (as shown in Table 5). The negative coefficient in this interaction term indicates that an increase in either power or time of heating or both together, decreased expansion ratio.

$$
\begin{aligned}
& E R=3.78+0.15 M+0.27 P+0.46 T-\ldots \\
& \ldots 1.14 P T-0.28 M^{2}-0.49 P^{2}-1.3 T^{2}
\end{aligned}
$$

Figure 6 shows the response surface for expansion ratio at the third factor $(\mathrm{M})$ at the central point. Expansion ratio initially increased rapidly with time of heating and power followed by a decreasing trend with further increase in these variables.

\subsection{Optimization of microwave popping of paddy}

Numerical optimization of the above equations (6 and 7) was carried out using a designated software program (Design Expert 7) as stated in the previous section. The response criteria for optimization were chosen for maximization of popping percentage and expansion ratio. On the basis of highest desirability value of 0.866 , the optimized values of independent parameters $\mathrm{M}$, $\mathrm{T}$ and $\mathrm{P}$ were estimated to be $15 \%, 1000 \mathrm{~W}$ and $80 \mathrm{~s}$, which gave percentage of popping and ex- 
$56 \mid$ Swarnakar et al.
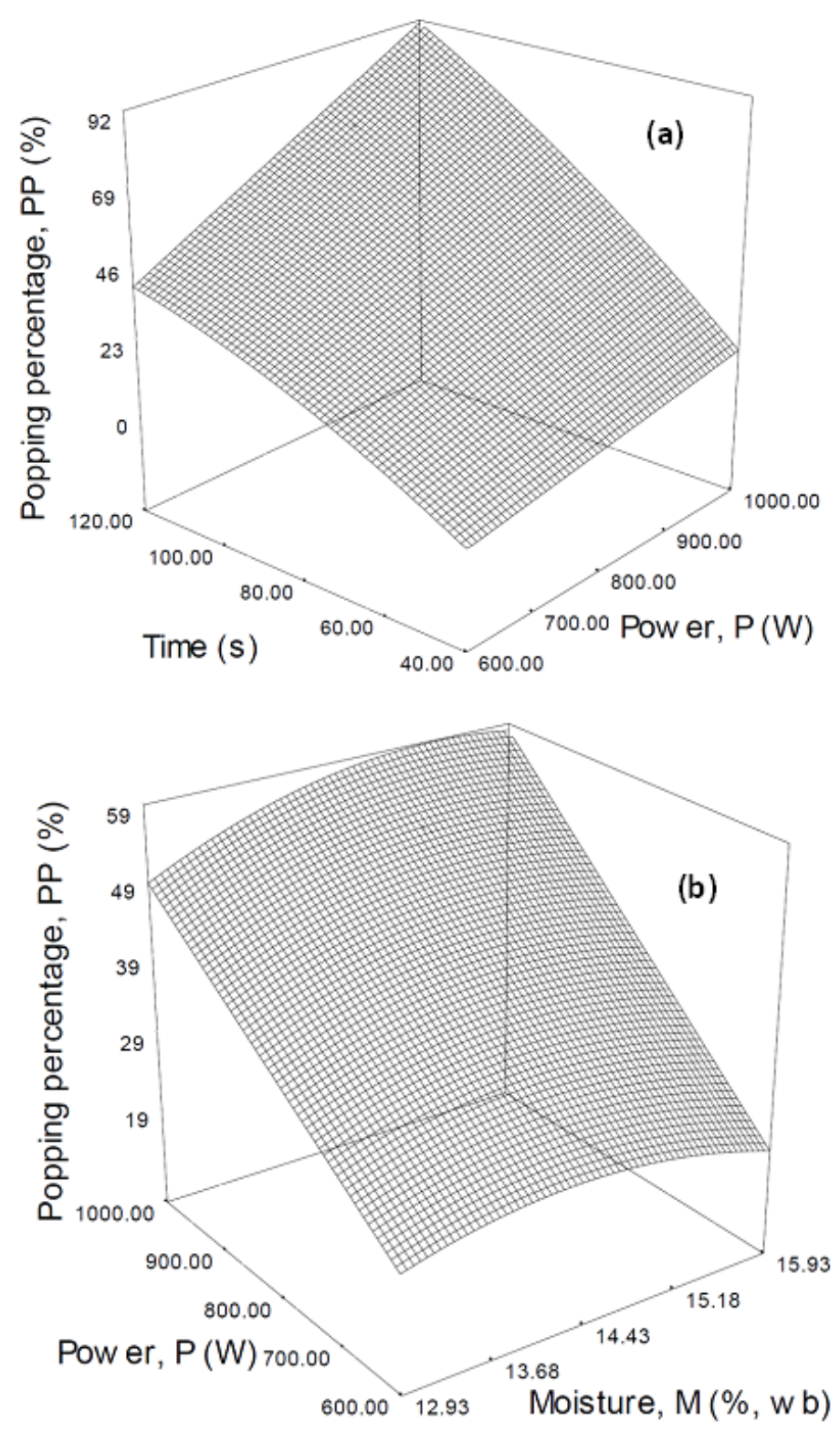

Figure 5: Response surface showing the effects of interaction terms on popping percentage. (a) Time and power, (b) Power and moisture content 
Microwave popping characteristics of paddy $\mid 57$

Table 4: Analysis of variance (ANOVA) for popping percentage of paddy

\begin{tabular}{llllll}
\hline Source & Sum of Squares & df & Mean Square & F Value & p Value \\
\hline Model & 16108.36 & 7 & 2301.19 & 80.20 & 0.0001 \\
$\mathrm{M}$ & 90.1 & 1 & 90.10 & 3.14 & 0.0840 \\
$\mathrm{P}^{*}$ & 4879.35 & 1 & 4879.35 & 170.06 & 0.0001 \\
$\mathrm{~T}^{*}$ & 7488.11 & 1 & 7488.11 & 260.98 & 0.0001 \\
$\mathrm{M} \times \mathrm{P}^{* *}$ & 120.10 & 1 & 120.10 & 4.19 & 0.0474 \\
$\mathrm{P} \times \mathrm{T}^{*}$ & 589.79 & 1 & 589.79 & 20.56 & 0.0001 \\
$\mathrm{M}^{2 * *}$ & 161.01 & 1 & 161.01 & 5.61 & 0.0228 \\
$\mathrm{~T}^{2 * * *}$ & 97.90 & 1 & 97.90 & 3.41 & 0.0721 \\
\hline $\mathrm{R}^{2}=0.933 ; \mathrm{R}^{2}\left(\right.$ adjusted) $=0.921, \mathrm{R}^{2}($ predicted $)=0.903$, C.V. $=18.99 \%$ \\
\hline \multicolumn{2}{r}{ significant at $\mathrm{p}<0.01 \%,{ }^{* *}$ significant at $\mathrm{p}<0.05 \%,{ }^{* * *}$ significant at $\mathrm{p}<0.1 \%$}
\end{tabular}

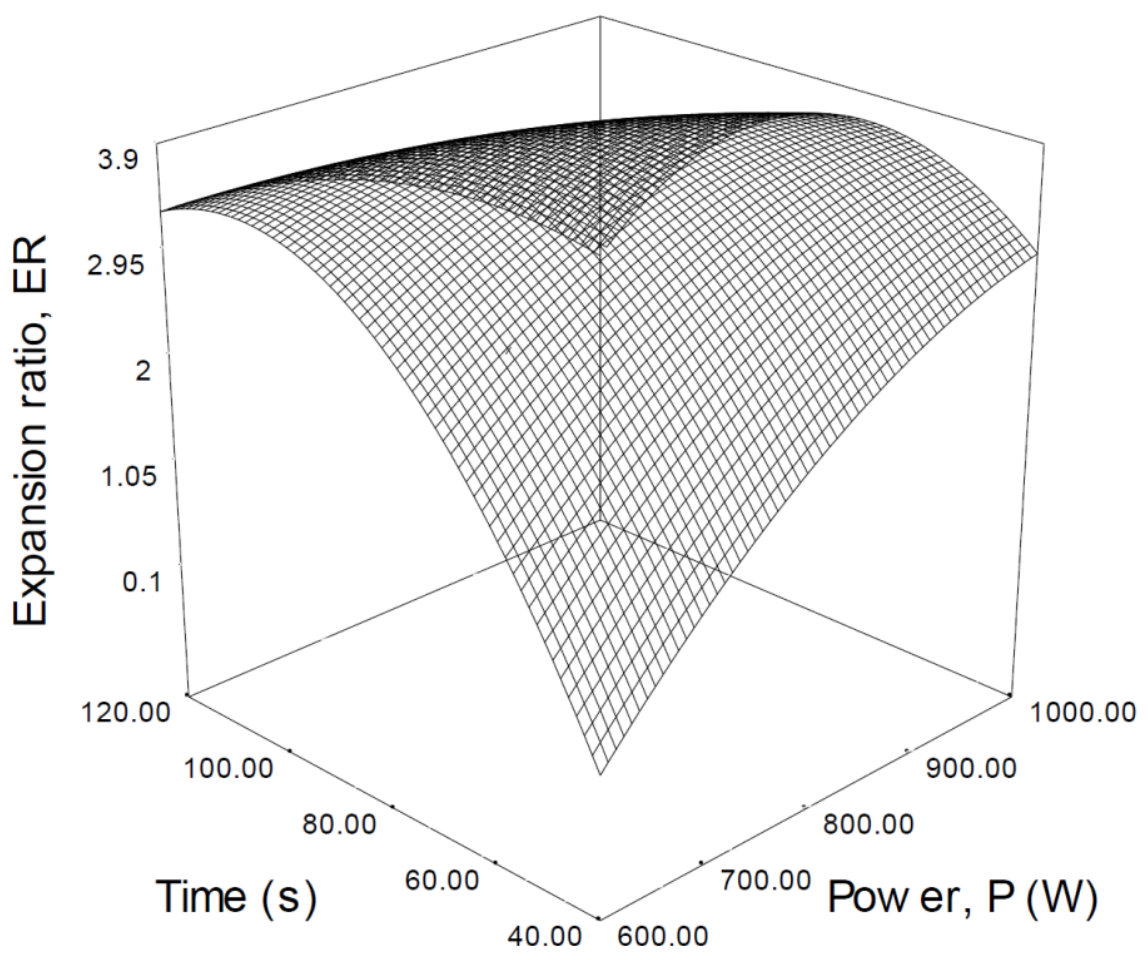

Figure 6: Response surface showing the effect of power and time on expansion ratio 
58 Swarnakar et al.

Table 5: Analysis of variance (ANOVA) for expansion ratio of paddy

\begin{tabular}{llllll}
\hline Source & Sum of Squares & df & Mean Square & F Value & $\mathrm{p}$ Value \\
\hline Model & 49.79 & 7 & 7.11 & 69.60 & 0.0001 \\
$\mathrm{M}^{* *}$ & 0.57 & 1 & 0.57 & 5.60 & 0.0229 \\
$\mathrm{P}^{* *}$ & 1.15 & 1 & 1.15 & 11.30 & 0.0017 \\
$\mathrm{~T}^{* * *}$ & 1.78 & 1 & 1.78 & 17.39 & 0.0002 \\
$\mathrm{P} \times \mathrm{T}^{*}$ & 8.83 & 1 & 8.83 & 86.43 & 0.0001 \\
$\mathrm{M} 2^{* *}$ & 0.79 & 1 & 0.79 & 7.68 & 0.0084 \\
$\mathrm{P}^{*}$ & 1.89 & 1 & 1.89 & 18.47 & 0.0001 \\
$\mathrm{~T}^{*}$ & 7.97 & 1 & 7.97 & 78.03 & 0.0001 \\
\hline $\mathrm{R}^{2}=0.924, \mathrm{R}^{2}($ adjusted $)=0.910, \mathrm{R}^{2}$ (predicted) $=0.892, \mathrm{C} . \mathrm{V} .=11.49 \%$ \\
\hline \multicolumn{4}{r}{ significant at $\mathrm{p}<0.01 \%,{ }^{* *}$ significant at $\mathrm{p}<0.05 \%,{ }^{* *}$ significant at $\mathrm{p}<0.1 \%$}
\end{tabular}

pansion ratio of 58.73 and 3.58 , respectively

\section{Conclusions}

Microwave popping of paddy could be carried out using domestic microwave oven at different power and time combinations. Highest popping could be achieved with paddy containing moisture content between 14 and 15\% (wb). Time of heating is a sensitive parameter for sharp rise in popping percentage as compared to power level. Increasing grain moisture maximizes popping up to a certain limit. Short time heating gives higher expansion ratio than prolonged heating. A maximum popping percentage of 63.47 and expansion ratio of 4.42 could be obtained at energy level of 68 - 80 kJ. Maximum power level could be employed if more popping of paddy is desired. Short time heating at moderate power level should be used for maximization of expansion ratio. Popping percentage as high as $58.73 \%$ and expansion ratio of 3.58 could be obtained under optimized condition of power $(1000 \mathrm{~W})$ and time $(80 \mathrm{~s})$ of heating and moisture content (15\%) of paddy. Both popping percentage and expansion ratio were predicted well with the regression equations given herein.

\section{References}

AOAC. (1990). Official methods of analysis (15th edn.). Washington, DC: Association of Official Analytical Chemists Inc.
Bhat Upadya, V. G., Bhat, R. S., Shenoy, V. V., \& Salimath, P. M. (2008). Physico-chemical characterization of popping-Special Rice Accessions. Karnataka Journal of Agricultural Sciences, $21(2), 184-186$.

Chakravorty, A. \& Ghosh, P. D. (2012). Grain dimension studies in view of kernel weight development in traditional rice of west bengal. International Journal of Biosciences, 2(10-2), 95-102.

Chinnaswamy, R. \& Bhattacharya, K. R. (1983). Studies on expanded rice - optimum processing conditions. Journal of Food Science, 48(6), 1604-1608. doi:10.1111/j.1365-2621. 1983.tb05042.x

Juliano, B. O. (1993). Rice in human nutrition. FAO food and nutrition series. Food and Agriculture Organization of the United Nations. Retrieved from http://books.google. pt/books?id=voPQLFEI5fgC

Maisont, S. \& Narkrugsa, W. (2009). Effects of some physicochemical properties of paddy rice varieties on puffing qualities by microwave "original". Kasetsart Journal, Natural Sciences, 43(3), 566-575.

Maisont, S. \& Narkrugsa, W. (2010). Effects of salt, moisture content and microwave power on puffing qualities of puffed rice. Kasetsart Journal Natural Science, $44(2)$, 251-261.

Mohapatra, M. \& Das, S. K. (2011). Effect of process parameters and optimization on microwave puffing performance of rice. $R e$ - 
Microwave popping characteristics of paddy $\mid 59$

search Journal of Chemistry and Environment, 15(2), 454-461.

Murugesan, G. \& Bhattacharya, K. R. (1986). Studies on puffed rice .1. effect of processing conditions. Journal of Food Science and Technology-Mysore, 23(4), 197-202.

Murugesan, G. \& Bhattacharya, K. R. (1991a). Basis for varietal difference in popping expansion of rice. Journal of Cereal Science, 13(1), 71-83.

Murugesan, G. \& Bhattacharya, K. R. (1991b). Effect of some pretreatments on popping expansion of rice. Journal of Cereal Science, 13(1), 85-92.

Nath, A., Chattopadhyay, P. K., \& Majumdar, G. C. (2007). High temperature short time air puffed ready-to-eat (rte) potato snacks: process parameter optimization. Journal of Food Engineering, 80(3), 770-780. doi:10. 1016/j.jfoodeng.2006.07.006

NIST. (2012). National Institute of Standards and Technology. Engineering Statistics Handbook, e-Handbook of Statistical Methods, U.S Commerce Department Technology Administration: NIST/SEMATECH. 9th August 2013 Chapter 5. Retrieved from http : //www.itl.nist.gov/div898/handbook/

Panlasigui, L. N., Thompson, L. U., Juliano, B. O., Perez, C. M., Yiu, S. H., \& Greenberg, G. R. (1991). Rice varieties with similar amylose content differ in starch digestibility and glycemic response in humans. American Journal of Clinical Nutrition, 54(5), 871-877.

Singh, J. \& Singh, N. (1999). Effects of different ingredients and microwave power on popping characteristics of popcorn. Journal of Food Engineering, 42(3), 161-165. doi:10. 1016/S0260-8774(99)00114-4

Song, A. \& Eckhoff, S. (1994). Optimum popping moisture-content for popcorn kernels of different sizes. Cereal Chemistry, 71(5), 458-460.

Srinivas, T. \& Desikachar, H. S. R. (1973). Factors affecting the puffing quality of paddy. Journal of the Science of Food and Agriculture, 24(8), 883-891. doi:10.1002/jsfa. 2740240804 